\title{
Recruitment of medical residents much more intense in US than in Canada
}

\author{
n Cite as: CMAJ 2019 July 22;191:E824-5. doi: 10.1503/cmaj.109-5776
}

Posted on cmajnews.com on July 2, 2019.

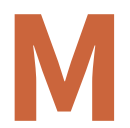

any final-year resident physicians in the United States are facing more job offers than they can handle, as recruiting companies scramble to fill vacancies around the country. A survey by the physician search firm Merritt Hawkins found that $66 \%$ of residents received more than 51 job solicitations during their training; 45\% received 100 or more.

"We've done this survey for 10 years, and we've never seen higher numbers," says Kurt Mosely, vice president of strategic alliances at Merritt Hawkins. "Especially in psychiatry, where the average is over 100 practice opportunities."

The recruiting frenzy is driven by increasing demand for doctors, says Mosely. The Association of American Medical Colleges estimates there will be a shortage in the US of more than 122000 physicians by 2032 .

Although parts of Canada also face physician shortages, few Canadian residents would complain they are overwhelmed with job offers. "They have options, but I have never heard of them being harassed by recruiters," says Dr. Geneviève Moineau, president of the Association of Faculties of Medicine of Canada. In some of the more technical and resource-intensive specialties, there are too few jobs in Canada.

Some US recruiters also target Canadian doctors but the numbers moving south don't seem to be huge, says Moineau. "There was a lot of concern over brain drain several years ago, but my impression is that the trend has slowed down significantly, especially in the last few years because of the political situation."
Jamie Sitar, chair of the board of the Canadian Association of Staff Physician Recruiters, says Canada's public health care system means there is less competition between hospitals and health systems for doctors. "That leads to a less intense recruitment environment, where over time you are trying to balance local resource allocation with long-term population health planning," he says. "This supports broader national and regional collaboration."

Also, regional health care recruitment organizations in Canada, like HealthForce Ontario and Health Match BC, offer onestop shops to understand regional opportunities and support doctors during the recruitment process and throughout their careers. "So even though physician demand continues to be a real challenge facing most Canadian communities, these organizations

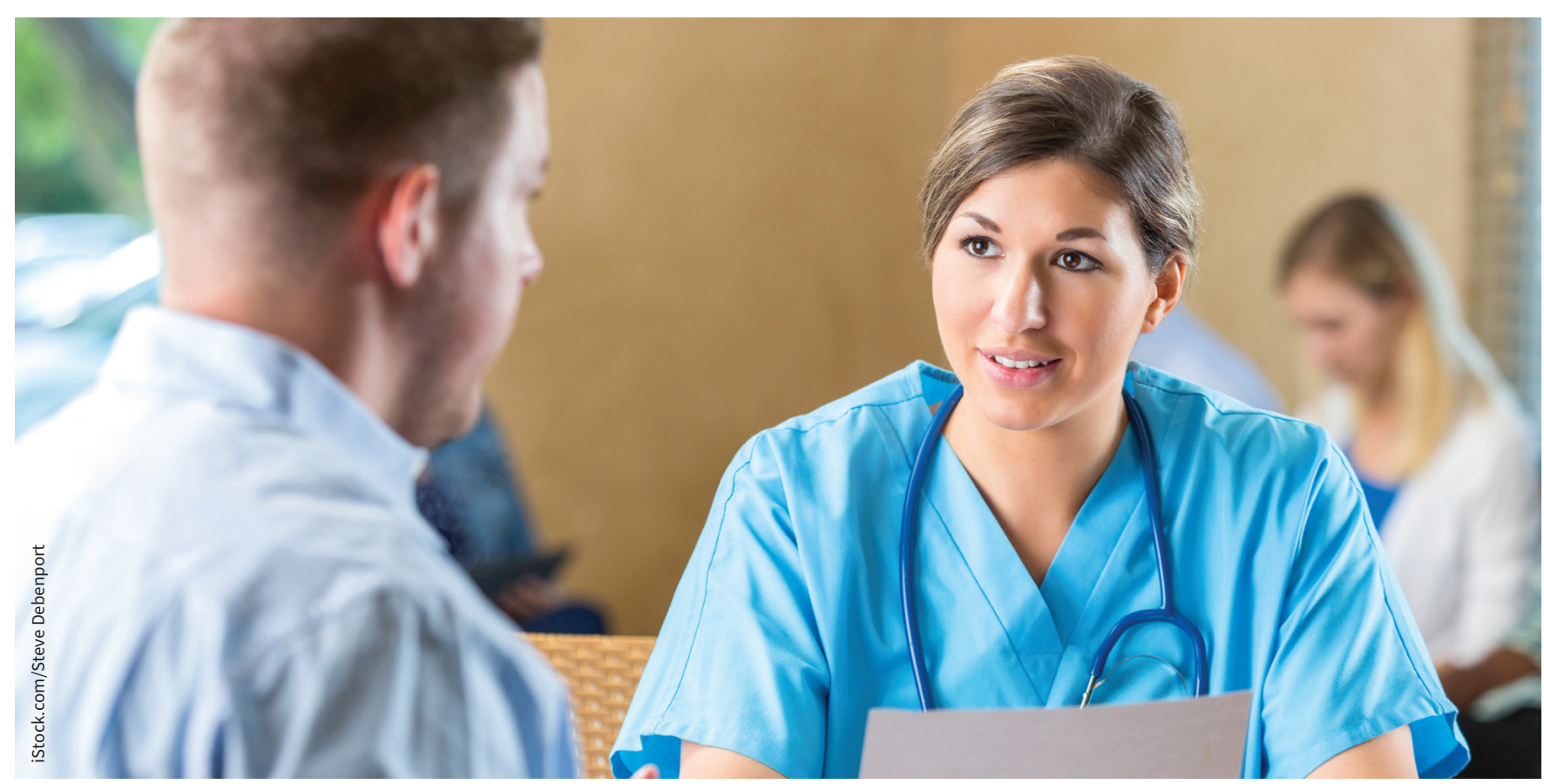

Many US medical residents are overwhelmed with job offers from recruiters. 
help to reduce the number of individual people who may be reaching out to the physicians from a recruitment perspective, contrasting the US findings," says Sitar.

Indeed, physician recruitment is so intense in the US that $64 \%$ of final-year residents who responded to the Merritt Hawkins survey said the level of contact from recruiters was "too much."

"It's nice to be wanted, but they get so many offers and they don't know how to evaluate them," says Mosely. "They need training on the business side of medicine, and what to look for in a contract."

That resonates with Dr. Matthew Lecuyer, who just completed a fellowship in pediatric emergency medicine at Brown University. "We don't get good business training in medicine at all, or any training in negotiation," he says. "That's an art I had to learn by trial and error."

Lecuyer says he had numerous job offers and found it hard to make a decision, having to balance where he wanted to live with good academic opportunities and job prospects for his partner, who is also a physician. They both ended up taking positions at Children's National Health System in Washington, DC.

Many residents find it difficult to choose a job because it's the first time they've had to make a career decision alone, says Lecuyer. For residency and fellowship positions, the final decision is generally made by a matching system, so much of the burden of decision-making is taken away from the doctor. Lecuyer credits good advice from his mentor and the American Medical Association's "Making the Rounds" podcast for helping him make a decision he is happy with.

Not everyone gets swamped with offers, however; it depends on your subspecialty and where you want to practise, says Dr. Michael Lubrano, an anesthesiologist who recently completed a fellowship in pain medicine at Harvard Medical School. In pain medicine, there is an enormous need for doctors, but the job market in big cities is often saturated.

"There are a lot of jobs if you are willing to leave a major city," says Lubrano.

Brian Owens, St. Stephen, NB 